\title{
Asymptomatic contrast medium extravasation
}

\author{
Yoh Arita, ${ }^{1}$ Shouta Bun, ${ }^{2}$ Takatsugu Segawa, ${ }^{1}$ Shinji Hasegawa ${ }^{1}$
}

${ }^{1}$ Department of Cardiology, Japan Community Healthcare Organization (JCHO) Osaka Hospital, Osaka, Japan ${ }^{2}$ Department of Dermatology, Japan Community Healthcare Organization (JCHO) Osaka Hospital, Osaka, Japan

\section{Correspondence to}

Dr Yoh Arita,

arita-yo@osaka.jcho.go.jp

Accepted 30 October 2017

\section{DESCRIPTION}

A 72-year-old man was referred for a contrast-enhanced multidetector coronary CT examination. A physician tried to place an angiocatheter (BD Insyte Autoguard Winged, 20G, $1.1 \times 25 \mathrm{~mm}$ ) into the right median basilic vein; however, the vein could not be punctured correctly because it was difficult to detect owing to the tortuosity of the patient's vascular network. Therefore, the median cephalic vein was punctured. However, when the entire outer plastic tube was placed into the vein, the intravenous infusion failed to drop. When the outer plastic tube was pulled back by about $2 \mathrm{~mm}$, the infusion was able to drop properly and the tube was fixed at that position. Before the infusion of contrast medium (CM), landiolol was injected through this catheter to reduce the patient's heart rate (HR). When the physician injected landiolol by hand, no resistance was felt and the HR of the patient was reduced from 81 to $73 \mathrm{bpm}$. Thereafter, $62 \mathrm{~mL}(4.7 \mathrm{~mL} / \mathrm{s})$ of $\mathrm{CM}$ was injected by using an automated injector (Nemoto, Dual Shot GX7). During the injection, the patient did not report any symptoms and the pressure monitor did not detect pressure higher than $13 \mathrm{~kg} / \mathrm{cm}^{2}$, which is the upper limit of our protocol (figure 1A). The wave shape was only slightly different from that recorded from the same patient during an accurate infusion (figure 1B). As there was no contrast enhancement on CT, the physician examined the patient and found slight swelling in the arm. A simple radiograph of the right arm showed collection of CM in superficial soft tissues of the antecubital fossa and subfascial extravasation in the biceps muscle compartment (figure 2A). Although the patient did not have diabetes, a peripheral disease, or an impending skin necrosis, which are the usual indications for incision and drainage, he was referred to a dermatologist before his symptom and condition become worse. He underwent skin incisions and drainage of CM. The CM disappeared 1 day after drainage (figure $2 \mathrm{~B}$ ).
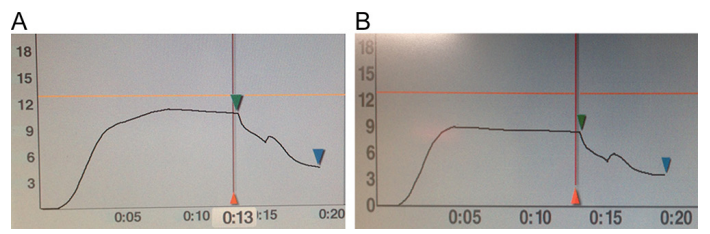

Figure 1 Pressure monitor results during infusion of contrast medium. The vertical axis shows the pressure $\left(\mathrm{kg} / \mathrm{cm}^{2}\right)$ and the horizontal axis shows the infusion time (s). (A) Pressure monitor results when extravasation was present. (B) Pressure monitor results in the same patient when extravasation was absent.
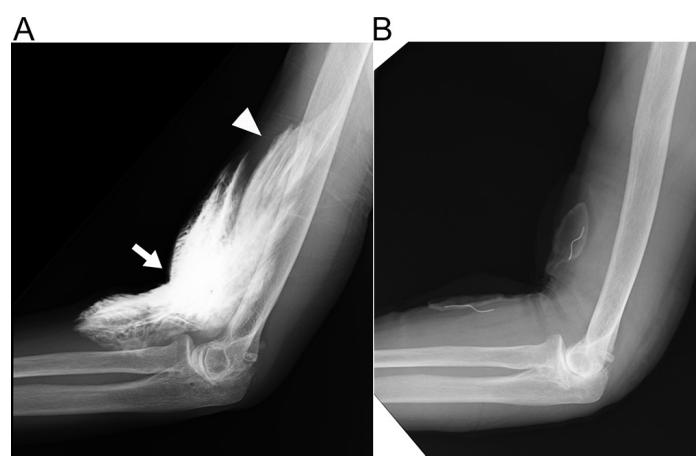

Figure 2 Simple radiograph of the right arm. (A) Contrast medium (CM) in superficial soft tissues of the antecubital fossa (arrow) and subfascial extravasation of the biceps muscle compartment (arrowhead) were detected. (B) CM was undetectable 1 day after drainage.

The incidence of extravasation during contrast-enhanced CT with power injection is estimated to be $0.45 \% .^{1}$ When extravasation occurs, patients usually experience symptoms such as pain, discomfort, numbness, burning sensation and stiffness in the injection site. In a previous study, 79\% of patients had localised swelling after extravasation, 24\% had pain, and $8 \%$ were asymptomatic. ${ }^{2}$ The risk factors for CM extravasation depend on the injection technique and patient characteristics. ${ }^{3}$ In this case, use of an automated injector, puncture of a suboptimal site, atrophy of the subcutaneous cellular tissue and fragile veins of the elderly patient were the risk factors. Interestingly, the pressure monitor of the automated injector could not detect the abnormal injection and the pressure wave was similar to that of a normal infusion.

This case report reminds clinicians about the risk of CM extravasation and of placing too much confidence in the use of a pressure monitor.

\section{Learning points}

- Asymptomatic extravasation may occur when using an automated injector.

- The pressure monitor of an automated injector cannot always detect extravasation.

Acknowledgements We thank Takaki Fujiwara for providing the images of pressure monitor.

Contributors YA collated information regarding the case and performed the needle puncture. SB treated this patient for extravasation. TS involved in the management of the case. YA and $\mathrm{SH}$ contributed to writing the manuscript. All authors have read and approved the final manuscript.

Competing interests None declared.

Patient consent Obtained. 
Provenance and peer review Not commissioned; externally peer reviewed.

(c) BMJ Publishing Group Ltd (unless otherwise stated in the text of the article) 2017. All rights reserved. No commercial use is permitted unless otherwise expressly granted.

\section{REFERENCES}

1 Chew FS. Extravasation of iodinated contrast medium during CT: self-assessment module. AJR Am J Roentgenol 2010;195:S80-S85.
2 Wang CL, Cohan RH, Ellis JH, et al. Frequency, management, and outcome of extravasation of nonionic iodinated contrast medium in 69,657 intravenous injections. Radiology 2007;243:80-7.

3 Pacheco Compaña FJ, Gago Vidal B, Méndez Díaz C. [Extravasation of contrast media at the puncture site: strategies for managment]. Radiologia 2014; $56: 295-302$

Copyright 2017 BMJ Publishing Group. All rights reserved. For permission to reuse any of this content visit http://group.bmj.com/group/rights-licensing/permissions.

BMJ Case Report Fellows may re-use this article for personal use and teaching without any further permission.

Become a Fellow of BMJ Case Reports today and you can:

- Submit as many cases as you like

- Enjoy fast sympathetic peer review and rapid publication of accepted articles

- Access all the published articles

Re-use any of the published material for personal use and teaching without further permission

For information on Institutional Fellowships contact consortiasales@bmjgroup.com

Visit casereports.bmj.com for more articles like this and to become a Fellow 